\title{
The Big Picture
}

Dr Dashrath Kafle

Chief Editor

"Education is the most powerful weapon which you can use to change the world"

Nelson Mandela

The journey of thousand miles begins with a single step. When I look back into the yesteryears, I have the feeling that the process of starting a journal dedicated to orthodontic specialty was conceived when there were only seven orthodontists for the whole country. It was not too long back!!! That was the level of commitment to uplift our profession, patient care and improve ourselves. The first issue of Orthodontic Jopurnal of Nepal(OJN) was published in November 2011 . That was the historic moment in the history of nepalese orthodontics. Although the publication of journal dedicated to dentistry, the Journal of Nepal Dental Association(JNDA) was started in 1999, however the regularity of the publications was always an issue.

OJN had a number of challenges and still has many. The challenges we had then were to receive enough materials/ articles to be able to bring the issues on time as well as the quality of the submissions. With time those problems are no more there. Around the same time, the number of dental faculties increased which led to opening of number of dental colleges in Nepal. The faculties involved in academia were involved in research as well. At the same time few old dental colleges started post graduate program in orthodontics. That was again another milestone in the history of orthodontics. More and more residents started conducting meaningful research and preceptors were also equally involved in their projects. Soon OJN was one of the reputed platform to share and disseminate research done by students and our colleagues. This drive was spread over to interdisciplinary specialties which resulted submissions from other specialties interrelated to orthodontics. That was not the end of the story!!! OJN was indexed in some of the popular indexing sites including Nepjol, Index Copernicus and Hinari to name few. This helped OJN to have wider reach to scholarly world and more downloads from readers. Because of the broadening of the reader base, we then started getting submissions not only from Nepal but also from round the globe. Now OJN is on the verge of establishing itself as one of the reputed name in the list of orthodontic journals. This is an unique opportunity for a specialty journal which stated from developing country like Nepal to reach globally. However this opportunity is associated with number challenges. The sustainability of the journal, the cost of bringing printed version, maintaining as well as improving the quality of the accepted articles as well as bringing issues on time are some of the noted challenges at this moment. There had been great contribution from the previous editorial team to bring the journal into this shape, especially the past Editor in chief. There is no one who can supplement his idea, energy, dedication and passion.

There will not be any substantial change in the format of the journal. The new editorial team will focus mainly on quick processing of the submitted articles that includes peer reviewing, corresponding with the authors as well as timely decision. From the next issue, we hope to give our authors decision of their article within two months of submission. We will try to help our colleagues and readers with more clinically oriented articles especially in the case reports and clinical tips section. 2019 will be the year of organization and consolidation. Team OJN will definitely working hard to be listed in PUBMED. Help us, be with us, and believe in us. Dear readers we will come upto your expectation. 